\title{
Economic Evaluation on the Production of Poly- DADMAC and Sepiolite Nanocomposite
}

\author{
Dita Ayu Rosmawati ${ }^{1}$, Azzahra Annur Rizqia ${ }^{1}$, Sifathul Jannah ${ }^{1}$, Nissa Nur \\ Azizah2 $^{2}$ dan Asep Bayu Dani Nandiyanto ${ }^{1}$ \\ 1Departemen Pendidikan Kimia, Universitas Pendidikan Indonesia, Indonesia \\ 2Departemen Pendidikan Ilmu Komputer, Universitas Pendidikan Indonesia, Indonesia
}

Email: *nandiyanto@upi.edu

\begin{abstract}
Some agricultural wastes are not suitable for direct disposal to standard sewage treatment plants and pre-treatment is required to avoid clogging by colloidal materials. One of the pre-treatment stages is coagulation and flocculation. In several studies, the mixture of polymer and clay fulfills the properties of coagulant and flocculant materials. A mixture of poly-DADMAC polymer and sepiolite clay can be used as a coagoflocculant at the same time. This study aims to analyze whether a project to manufacture clay polymer nanocomposites is feasible or not. By taking into account various perspectives including engineering and economic perspectives, this project is considered prospective to be carried out. This is indicated by the increase in the Profitability Index (PI) value of 5.33658 in the third year from -0.00975 which was the PI value the previous year. In twenty-four hours, the project can produce approximately 8.25 tonnes of adsorbent. The total profit earned in one year reaches $719,738.04$ USD when run under ideal conditions. Apart from the results of the economic analysis mentioned, this project is also very effective in terms of time because it is simple and the raw materials needed are abundant.
\end{abstract}

\section{Introduction}

Nanocomposite is defined as a multi-phase material derived from a combination of two or more components, first is a matrix component as a continuous phase and second is a nanodimensional phase as a discontinuous phase with one dimension of nano size with a diameter of less than $100 \mathrm{~nm}$. Several types of composites have been developed by strengthening these composite compounds to polymers to increase their resistance to heat, mechanical and other barriers [1-2].

Water from some agricultural effluents (such as olive mills, wineries, pig farms, soybeans, or the coffee bean industry) is not suitable for discharge to standard sewage treatment plants, due to the large amount of organic and suspended matter. Annual production of black olive mill wastewater and highly toxic in Mediterranean olive-producing countries is estimated to be around 10-30 million $\mathrm{m}^{3}$. Disposal of such waste without treatment is known to cause serious environmental problems [3]. 
Coagulation and flocculation are processes that are often used in the primary purification of industrial wastewater (in some cases for secondary and tertiary treatment) [4-5]. Coagulation using chemical coagulants involves the incorporation of insoluble particles and dissolved organic matter into large aggregates to facilitate their transfer at subsequent stages of deposition, flotation and filtration [6]. Flocculation refers to the process by which unstable particles actually change into larger aggregates so that they can be separated from the wastewater. To achieve this effect, a series of industrial measures are used. In most cases, the process carried out is based on two separate stages, and in two separate tanks:

1. Neutralization of the charges to overcome electrostatic repulsion (yielding "coagulation")

2. Bridging between several relatively small particles to form larger aggregates that, due to their size and density, sink to the bottom of the vessel, leaving a clarified effluent (leading to "flocculation") [7].

Several studies have been reported on the examination of coagulation-flocculation aiming at performance optimization, that is selection of the most appropriate coagulant, determination of experimental conditions, assessment of $\mathrm{pH}$ effect and investigation of flocculant addition [8]. Aluminum sulfate (alum), ferrous sulfate, ferric chloride and ferric chloro-sulfate were commonly used as coagulants [9-10]. Iron salts were proved to be more efficient than aluminum ones, resulting in sufficient chemical oxygen demand (COD) reductions (up to $56 \%$ ), whereas the corresponding values in case of alum or lime addition were lower (39 or 18\%), respectively [11]. Additionally, high COD removal capacities

have been observed during the combined action of alum and lime for the treatment of stabilized leachates [12]. Furthermore, the addition of flocculants together with coagulants can increase the rate of floc deposition [10].

Addition of "coagulants" and "flocculants" at the same time usually yields in the destabilization of the colloidal suspension, followed by flocculation of large amounts of suspended matter, lowering total suspended solids (TSS), turbidity, and even chemical oxygen demand (COD). This, in turn, increases the following water treatment efficiency, thereby reducing environmental hazards [13].

The nanocomposite used in this study uses the mineral sepiolite clay and cationic polymer poly-DADMAC. The nanocomposites are also used as "coagoflocculants" to incorporate colloid neutralization (coagulation), achieved by the polymer-charged parts and bridging of the neutralized particles (flocculation), achieved by the fact that polymer chains are linked to denser and heavier anchoring particles; this may result in highly efficient wastewater pretreatment and reduction of TSS in a single treatment step [7]. Needle-like clay mineral sepiolite as anchoring particles and poly-DADMAC linear cationic polymer as bridging ribbon.

For efficient coagoflocculation, the anchoring particles should have the following properties :

1. A size or diameter of less than $0.5 \mu \mathrm{m}$ in at least one dimension, resulting in a large specific surface area

2. The ability to adsorb cationic polymers in strong interactions

3. The bulk density of the particles should be larger than the density of the effluents.

Therefore, anchoring particles might be acicular (needlelike) clay minerals such as sepiolite and palygorskite or clay smectites such as montmorillonite, hectorite, laponite, and 

or even powdered activated carbon [14].

The stability of the dispersion is related to its particle size, density and charge. Other than that, in organic waste colloids usually have a negative charge, cationic polymers must be used to neutralize the colloidal charge. In addition, the polymer must have medium to long chains with charges spread throughout to allow a bridging effect. The polymer must also be relatively water soluble to allow efficient distribution in the effluent. Therefore, suitable polymers might be :

1. Water-soluble linear polymers such as poly-DADMAC or cationic polyacrylamide;

2. Polyquaternium molecules such as quaternary hydroxyethylcellulose ethoxylate;

3. Cationic biopolymers such as cationic guar gum or chitosan;

4. Polymers with aromatic rings such as poly-4-vinylpyridine-costyrene and additional styrene-based cationic copolymers. The latter might even yield in additional $\Pi-\Pi$ interactions with organic colloids, enabling more efficient coagoflocculation [13].

The purpose of this study was to evaluate the economic feasibility of production clay polymer nanocomposites using DADMAC polymer and sepiolite. Several economic evaluation parameters used, such as GPM, IRR, ARR, NPV, CNPV, BEP, PBP, and PI were analyzed to determine the potential production of valuable materials from fishery waste. Then, the economic parameters are tested by changing various economic conditions, such as labor, sales, raw materials, utilities, and external conditions.

\section{Method}

\subsection{Polymer Clay Nanocomposite Synthesis Method}

Materials used in the manufacture of polymer clay nanocomposites are Sepiolite S9 clay with a size of $<200$ mesh (the authors obtained it from TOLSA SA (Madrid, Spain)), with 99\% pure mineral content, and poly (diallyldimethylammoniumchloride) (poly-DADMAC; molecular weight medium, 200,000-350,000 g/mol) (the author got it from Sigma-Aldrich). All ingredients are used without further treatment or purification.

The nanocomposites were prepared from sepiolite and poly-DADMAC at masses ranging between 3 and $2400 \mathrm{mg}$ polymer/g clay. A concentrate batch containing $100 \mathrm{~g}$ clay/ $\mathrm{kg}(10 \%)$ suspension was prepared. To produce nanocomposites, a solution containing the desired amount of polymer was prepared per gram of clay.

For example, the procedure for making a $10 \%$ stock suspension is as follows. The concentrated polymer (poly-DADMAC, usually $40 \% \mathrm{w} / \mathrm{w}$ ) is dissolved in a suitable amount of warm water to obtain a final volume of $500 \mathrm{~mL}$ containing $5 \mathrm{~g}$ of polymer. The solution was placed in a sonication bath to obtain a homogeneous solution. After that, the polymer solution is poured into a container with $50 \mathrm{~g}$ of sepiolite and stirred vigorously for 2 hours. The preparation is completed when the clay aggregate is no longer observed, and the viscosity of the suspension is relatively low. An increased viscosity indicates that the polymer is not dissolving well or the process has not been completed, because a $10 \%$ suspension of most clay minerals in water (without polymer) produces a paste that cannot be used efficiently [13].

\subsection{Energy and Mass Balance}

To make the engineering process and calculate the mass balance in the production of clay polymer nanocomposites, several stoichiometric assumptions are used, including :

a. The cost of all equipment is based on a commercially available online marketplace; 
b. The composition of DADMAC polymer with sepiolite clay is a ratio of 1:10 [13];

c. All reactants react perfectly, there are no by-products, the final product is just a polymer clay nanocomposite coagoflocculant.

d. In a one-day process, the total processing cycles are 3 cycles and 15 cycles/week.

From an engineering point of view, it is possible to increase the production of sepiolite poly-DADMAC nanocomposite because the capacity and quantity of the tools and materials used can be increased. To produce $110 \mathrm{~kg}$ of nanocomposite requires 1 reaction cycle of about $1000 \mathrm{~L}$ of water, $10 \mathrm{~kg}$ of DADMAC polymer, and $100 \mathrm{~kg}$ of sepiolite clay.

\subsection{Economic Evaluation}

The method used in this research is the method of economic feasibility analysis, which is calculated through a simple mathematical analysis. This method uses data obtained based on the average price of commercially available products in online shopping media (such as Bukalapak, Alibaba, Tokopedia, etc.). Some of the parameters used to assess the economic feasibility are described as follows :

a. Gross Profit Margin (GPM)

An analysis that estimates by subtracting the cost of goods sold from the cost of raw materials.

b. Break Even Point (BEP)

The minimum number of products that must be sold at a certain price to cover the total cost of production.

c. Average Rate of Return (ARR)

Total inflows during the investment period divided by the number of years in the investment period. This value is important for predicting the state of the project.

d. Net Present Value (NPV)

The value obtained from the project, takes into account expenses and income and uses discount rate considerations.

e. Cumulative Net Present Value (CNPV)

Calculate the total NPV value from the beginning of the construction of the plant to the end of the operation of the plant, which can be obtained as the sum of accumulated capital flows each year.

f. Internal Rate of Return (IRR)

IRR is a percentage that describes the average annual interest gain of all expenses and income of the same amount.

g. Profitability index (PI)

The index is used to determine the relationship between project costs and impacts.

h. Payback Period (PBP)

PBP is a calculation used to predict the length of time required for an investment to return to the total initial expenditure. PBP is calculated based on the time when the CNPV first reaches zero.

[15]

\subsection{Parameters in Economic Evaluation}

The feasibility test for the manufacture of clay polymer nanocomposites using sepiolite and DADMAC polymer was carried out by changing the ideal conditions to the worst conditions. Several variations of internal problems such as raw materials, utilities, labor 

The basic points of the variety of internal and external problems are:

a. Variations in raw materials, utilities, and labor salaries are from $80 \%$ to $120 \%$.

b. Variations in the number of sales, namely from $80 \%$ to $120 \%$

c. The tax variation is from $10 \%$ to $100 \%$.

\section{Result and Discussion}

\subsection{Engineering Perspective}

The process of making poly-DADMAC nanocomposite with sepiolite is shown in Figure 1. The process carried out is dissolving the DADMAC polymer using warm water from a water heater and then homogenizing it in a sonicator bath. To this solution was added sepiolite clay solids measuring $<200$ mesh. The mixture was then homogenized for 2 hours until it was evenly mixed and shaped like a paste [13].

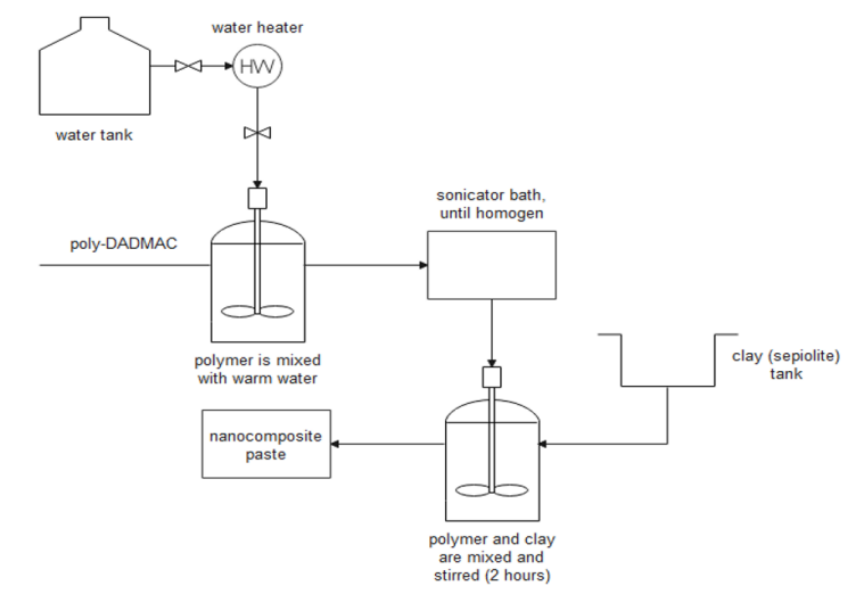

Figure 1. Process Flow Diagram (PFD) for production of nanocomposite from polyDADMAC and sepiolite

From an engineering point of view, the total cost used to purchase raw materials for one year is $508,780.80$ USD. Total annual sales is 3,049,200 USD with an annual profit of $719,738.04$ USD. The cost analysis of the required equipment is $4,818.05$ USD and the TIC should be less than 5,155.31 USD. This project requires a relatively low investment cost with a project life of 20 years to produce DADMAC sepiolite polymer nanocomposite with CNPV/TIC reaching $37.67 \%$ in year 20 and PBP achieved in third year.

\subsection{Ideal Condition}

Figure 2 shows a graph showing the relationship between lifetime (in years) plotted on the $x$-axis and the CNPV/TIC value (in \%) plotted on the y-axis. The graph shows an analysis of the CNPV/TIC value carried out during the 20 years of the project. During the first two years, this project did not provide a profit because the CNPV/TIC value obtained showed a negative value below zero (0). This is because at the beginning of the project, the project was still under development. The lowest CNPV/TIC value was achieved in the second year with a value of -0.0098 , then the CNPV/TIC value increased in the following year obtain reach 5.3366. In that year, the project experienced its first profit for three years of operation, this is called the Payback Period (PBP) where the project was able to recover the 
initial capital issued. In a period of 20 years, the CNPV/TIC value obtained reached 37,66668, which is the largest number that describes the highest profit that can be obtained by the project manager. With this analysis, the project of production nanocomposites based on polyDADMAC polymer mixed with sepiolite is considered feasible.

Then in Table 1, the complete data for the CNPV/TIC value is presented for a period of 20 years.

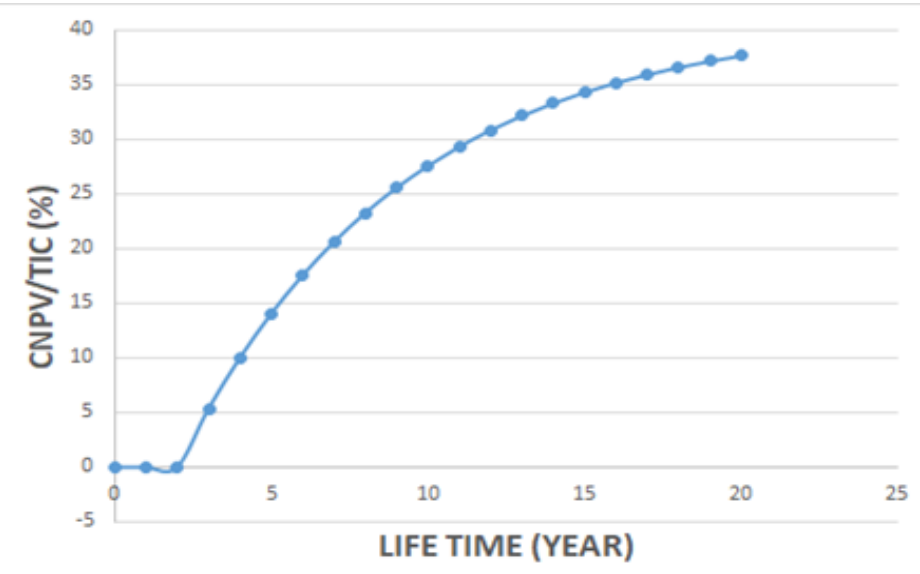

Figure 2. Graph of the value of CNPV/TIC under ideal conditions in a period of 20 years

Table 1. Annual CNPV values under ideal conditions

\begin{tabular}{|c|c|}
\hline CPNV/TIC & YEARS \\
\hline 0 & 0 \\
\hline-0.00059 & 2 \\
\hline-0.00975 & 3 \\
\hline 5.33658 & 4 \\
\hline 9.98556 & 5 \\
\hline 14.02815 & 6 \\
\hline 17.54345 & 7 \\
\hline 20.60023 & 8 \\
\hline 23.25830 & 9 \\
\hline 25.56966 & 10 \\
\hline 27.57954 & 11 \\
\hline 29.32727 & \\
\hline & \\
\hline
\end{tabular}


1(1)(2021) 162-172

Journal homepage: https://ojs.unikom.ac.id/index.php/injuratech

\begin{tabular}{|l|l|}
\hline 30.84703 & 12 \\
\hline 32.16856 & 13 \\
\hline 33.31771 & 14 \\
\hline 34.31698 & 15 \\
\hline 35.18591 & 16 \\
\hline 35.94150 & 17 \\
\hline 36.59853 & 18 \\
\hline 37.16986 & 19 \\
\hline 37.66668 & 20 \\
\hline
\end{tabular}

\subsection{Changes in External Conditions (Taxes)}

Economic evaluation of external factors might be one of the factors that can affect project success. One of the factors is the taxes to fund various public expenditures. Figure 3 shows a 20 year CNPV value graph with various tax changes, where the $y$-axis is CNPV/TIC and the $\mathrm{x}$-axis is lifetime (years).

The same results are shown at the initial one to three years due to variation in tax and CNPV project development. In addition, there was no income that year. The tax increase occurs two years later and will affect the CNPV value. When tax costs are added to the project, it will result in lower project profits. This is related to PBP, because the higher the tax, PBP for initial capital participation will be longer than ideal.

According to the PBP analysis, the funds required to pay the $10 \%, 25 \%, 50 \%, 75 \%$, and $100 \%$ tax will be realized in the third year, which means the business is feasible, because when the project reaches the payback period (PBP), the project profit will continued to increase until the $20^{\text {th }}$ year. The value of CNPV/TIC $10 \%, 25 \%, 50 \%, 75 \%, 100 \%$ in the 20 th year is $3.77 ; 9.41 ; 18.83 ; 28.25$; and $37.67 \%$. Therefore, the highest point for obtaining BEP or project profit or loss is $100 \%$.

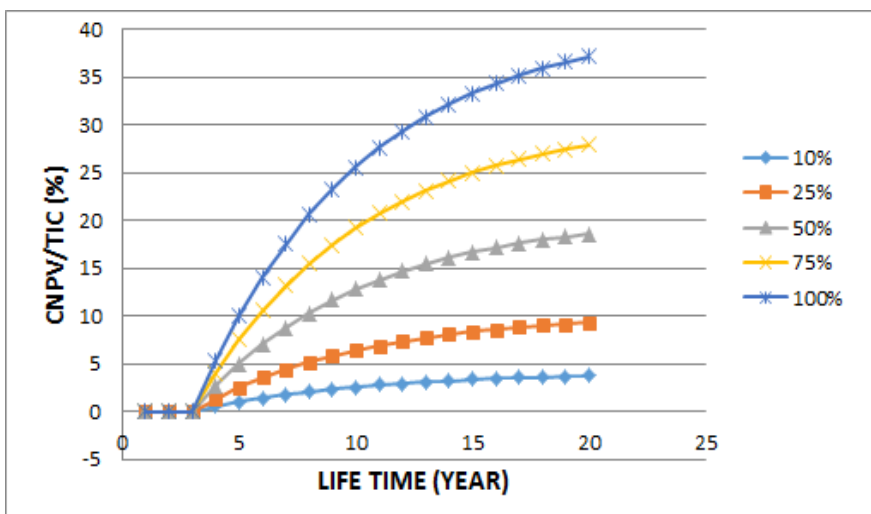

Figure 3. Graph of CNPV/TIC value on tax variations over a period of 20 years 


\subsection{Changes in Sales Amount Variations}

The analysis is carried out by varying the amount of the sales to $10 \%$ and $20 \%$. The ideal sales are $100 \%$, when the sales amount is decreased by $10 \%$ and $20 \%$, the sales are $90 \%$ and $80 \%$, but when the sales amounts are increased by $10 \%$ and $20 \%$, the sales are $110 \%$ and $120 \%$. The results of the PBP are shown in Figure 4. At the initial conditions of 0 to 2 years project with various variations showing the same CNPV/TIC value, this is because the project is still in the construction and development stage. The higher amount of sales, the profit will be increased. However, if there are conditions that cause a decrease in the number of product sales, the project's profits will fall from the ideal state.

Profits continue to increase after reaching the Payback Period (PBP) until the $20^{\text {th }}$ year. From the PBP analysis, the funds will return on the third year sales in every variation in the number of sales. The profit increased every year as sales increased from ideal conditions. The value of CNPV/TIC in the 20th year for each variation of $80 \%, 90 \%, 100 \%, 110 \%$, and $120 \%$ is $36.98 ; 37.32 ; 37.67 ; 38.01$ and $38.36 \%$. So sales will still yield a profit if the amount of sales is more than $100 \%$ or less than $100 \%$ because it can be seen on the graph that it still shows a positive CNPV/TIC value.

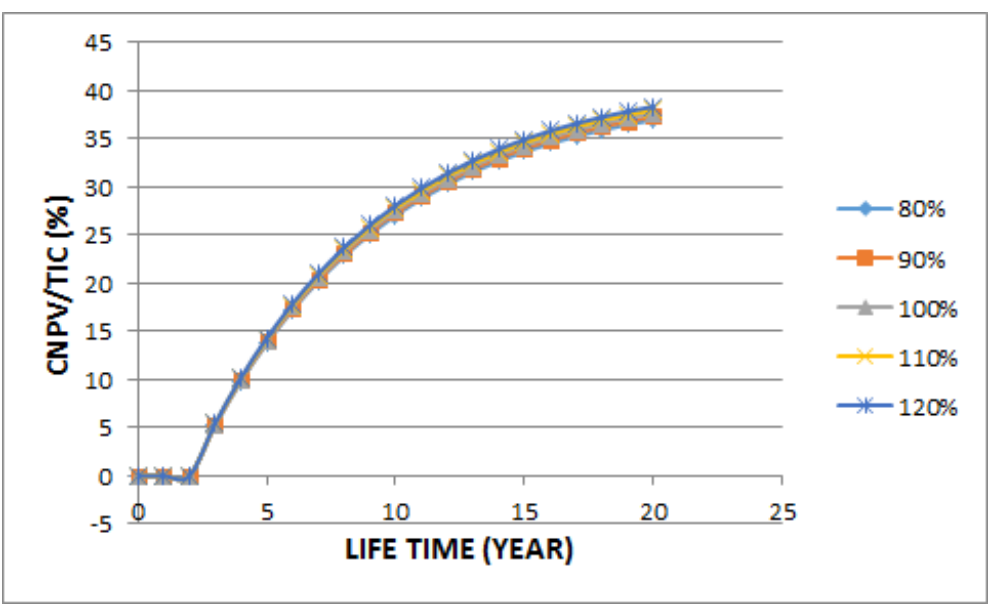

Figure 4. Graph of the value of CNPV/TIC on variations in the number of sales over a period of 20 years

\subsection{Changes in varying needs (raw materials, utilities and labor salaries)}

Many factors can affect the success of a project such as the raw materials, utilities such as electricity and water, as well as the salary for the labor to ensure the project goes well. Figure 5 shows the graph of the relationship between the value of CNPV/TIC with lifetime in various raw material prices. This analysis is carried out by varying the price of raw materials to $10-20 \%$ from the initial price. The price variations used in this analysis are $80 \%, 90 \%, 100 \%$, $110 \%$, and $120 \%$.

After being varied, the graph shows a similar trend. In the first two years, the project did not provide a profit, but in the following year there was a spike in the value of CNPV/TIC so that the project could earn a profit and experience PBP.

The value of CPNV/TIC in the $20^{\text {th }}$ year for variations in raw material prices $80 \%, 90 \%$, $100 \%, 110 \%$, and $120 \%$ respectively was $36.0204 ; 36.8436 ; 37.6667 ; 38.4898 ; 39.3129$. This value proves that the lower the price of raw materials, the higher profit will be generated. 
1(1)(2021) 162-172

Journal homepage: https://ojs.unikom.ac.id/index.php/injuratech

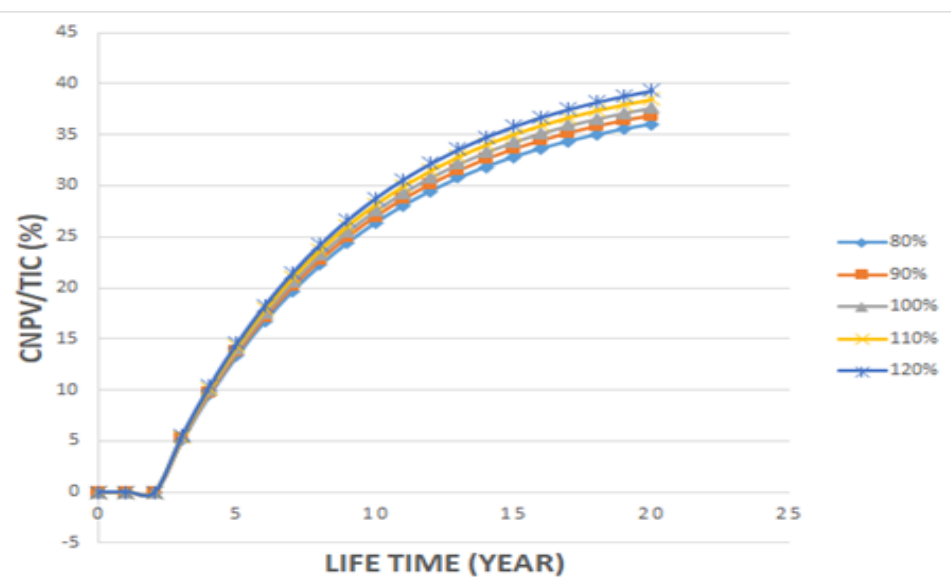

Figure 5. Graph of CNPV/TIC value on variations in raw material prices over a period of 20 years

The next factor is utility that the additional crucial requirements that need to be considered. The ideal sales are $100 \%$, when sales are decreased by $10 \%$ and $20 \%$, the sales are $90 \%$ and $80 \%$, but when sales are increased by $10 \%$ and $20 \%$, the sales are $110 \%$ and $120 \%$. The results of the PBP are shown in Figure 6. At the initial conditions of 0 to 2 years with various variations shows the same CNPV/TIC value because the project is still in the construction and development stage. The effect of utility prices on the value of CNPV/TIC can be seen after third years. The results of the analysis show that the variation in utility prices affects the value of CNPV/TIC, but the project can still run and generate profits. The value of CNPV/TIC in the $20^{\text {th }}$ year on the variation of utility prices $80 \%, 90 \%, 100 \%, 110 \%$, and $120 \%$ is $32.62 \% ; 35.14 \% ; 37.67 \% ; 40.19 \%$ and $42.72 \%$. The closest PBP is achieved in the second year with the largest profit of $32.62 \%$ can be obtained from the $80 \%$ utility variation.

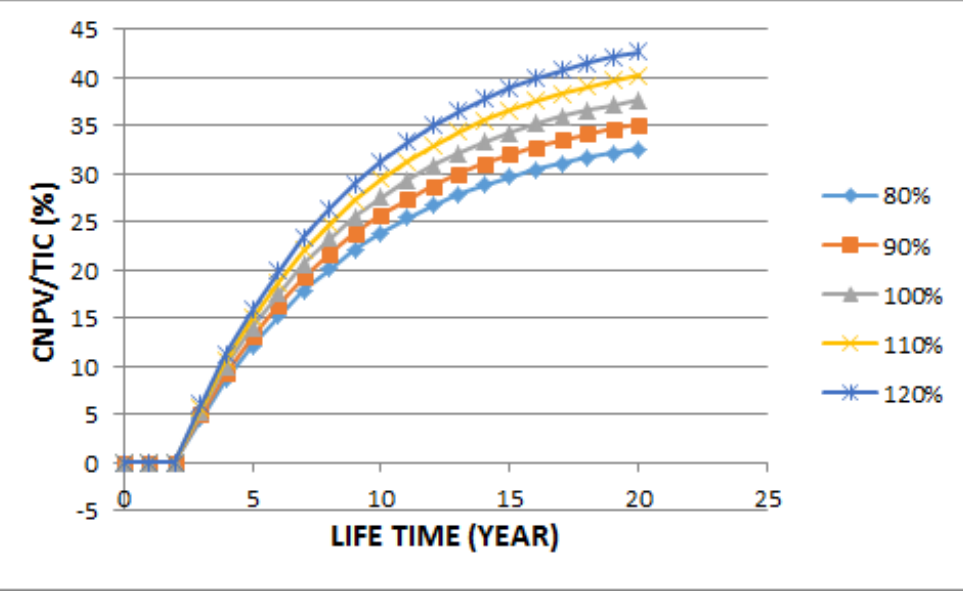

Figure 6. Graph of CNPV/TIC value on utility price variations over a period of 20 years

In addition, Figure 7 shows a similar graph but with varying labor salaries. The analysis is carried out by varying the salaries of workers by $10 \%$ and $20 \%$ from ideal conditions. The variations used to analyze changes in workers' salary are $80 \%, 90 \%, 100 \%, 110 \%$, and $120 \%$. At the initial conditions of the project (0-3 years), the CNPV/TIC value obtained is in the area below zero (0). This is because in that year, the project was undergoing development. 
Changes in worker's salary will certainly affect the CNPV/TIC curve because the profits to be obtained from the project depend on the worker's salary. The higher worker's salary, the lower the profit of the project. Variations of changes in salary changes analyzed were $80 \%$, $90 \%, 100 \%, 110 \%$, and $120 \%$. PBP is obtained in the third year the project is run, after the third year, the profit earned will continue to increase over time.

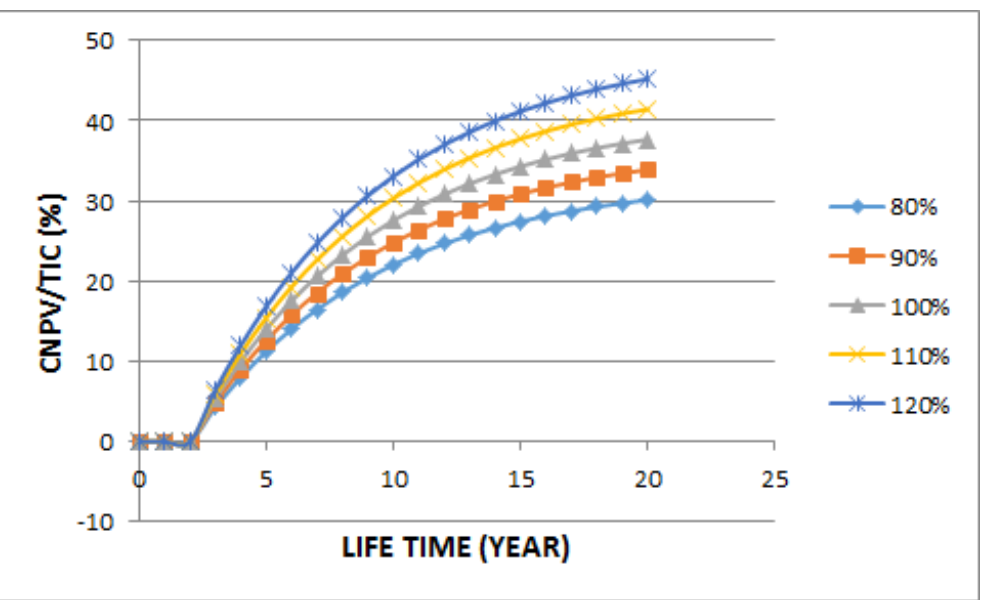

Figure 7. Graph of the value of CNPV/TIC on variations in labor salaries over a period of 20 years

\section{Conclusion}

Based on the results of the economic analysis carried out for various parameters, the project to produce clay polymer nanocomposites made from a mixture of poly-DADMAC with sepiolite is considered prospective when considering engineering and economic perspectives. This is indicated by the increase in the Profitability Index (PI) value of 5.33658 in the third year from -0.00975 which was the PI value the previous year. PBP analysis shows that the project can make a profit in the third year when the project is run, this is a good thing because PBP is obtained in a fairly short period of time. Thus, this project is considered to be able to compete in the market. In twenty-four hours, the project can produce approximately 8.25 tonnes of nanocomposite. The total profit earned in one year reaches $719,738.04$ USD when run under ideal conditions. Apart from the results of the economic analysis mentioned, this project is also considered very effective in terms of time because it is simple and the raw materials needed are abundant. From the results of the economic evaluation analysis, it can be concluded that this project prospective to be carried out.

\section{Acknowledgement}

We would like to thank all those who have participated in helping us complete this research, especially our supervisor, Mr. Asep Bayu Dani Nandiyanto, so that our research can be written as information for further research.

\section{References}

[1] Brody, AL., B.Bugusu, J.H. Han, C.K.Sand, and T.H. Mc.Hugh. (2008). Innovative food packaging solutions. Journal of Food Science 73(8): 107-116.

[2] Roy, R., Roy, R.A., Roy, D.M., (1986). Alternative perspectives on "quasicrystallinity": nonuniformity and nanocomposites. Material Letters 4, 323-328. 
[3] Jail, A., Boukhoubza, F., Nejmeddine, A., Sayadi, S., \& Hassani, L. (2010). Cotreatment of olive-mill and urban wastewaters by experimental stabilization ponds. Journal of Hazardous Materials, 176 (1-3), 893-900.

[4] Manu, B. (2007). Physico-chemical treatment of indigo dye wastewater. Coloration Technology, 123(3), 197-202. doi:10.1111/j.1478-4408.2007.00080.x

[5] Dovletoglou, O., Philippopoulos, C., \& Grigoropoulou, H. (2002). Coagulation for treatment of paint industry wastewater. Journal of Environmental Science and Health, Part A, 37(7), 1361-1377. doi:10.1081/ese-120005992

[6] Bratby, J. (2016). Coagulation and flocculation in water and wastewater treatment. Water Intelligence Online, 15(0), $9781780407500-9781780407500$. doi:10.2166/9781780407500

[7] Rytwo, G. (2011). Method for treatment of industrial organic effluents with nanocomposites of a polymer adsorbed on anchoring particles. Provisional Us patent application, $61(500,296)$

[8] Sletten, R.S., Benjamin, M.M., Horng, J.J., Ferguson, J.F., 1995. Physical-chemical treatment of landfill leachate for metals removal. Water Research. 29 (10), 2376-2386.

[9] Ehrig, H.J. (1984). Treatment of sanitary landfill leachate: biological treatment. Waste Management and Research. 2, 131-152.

[10] Amokrane, A., Comel, C., Veron, J. (1997). Landfill leachates pre-treatment by coagulation flocculation. Water Research, 31 (11), 2775-2782.

[11] Diamadopoulos, E., 1994. Characterization and treatment of recirculation-stabilized leachate. Water Research. 28 (12), 2439-2445.

[12] Loizidou, M., Kapetanios, E.G., Papadopoulos, A., 1992. Assessment of leachate characteristics and its treatability. Fresenius Environment Bulletin. 1, 748-753.

[13] Rytwo, G. (2012). The use of clay-polymer nanocomposites in wastewater pretreatment. The Scientific World Journal, 2012, 1-7. doi: 10.1100/2012/498503

[14] Alvarez, A. (1984). Sepiolite: properties and uses. In Developments in sedimentology (Vol. 37, pp. 253-287). Elsevier.

[15] Garrett, D.E. (1989). Chemical engineering economics. Heidelberg, Germany: Springer Netherlands. 